\title{
Formulation of Sustained-Release Diltiazem Matrix Tablets Using Hydrophilic Gum Blends
}

\author{
Afrasim Moin* and HG Shivakumar \\ JSS College of Pharmacy, JSS University, Mysore, Karnataka-570015, India.
}

\begin{abstract}
Purpose: To develop sustained release matrix tablets of diltiazem hydrochloride (DTZ) using karaya gum $(K)$ alone or in combination with locust bean gum (LB) and hydroxypropyl methylcellulose $(H)$.

Methods: Matrix tablets of DTZ were prepared at different ratios of drug:gum (1:1, 1:2, and 1:4) and of the gum blends ( $K, K / L B, K / H$ and $K / L B / H)$ by direct compression. The matrix tablets were evaluated for hardness, friability, in vitro release and drug content. The formulations were also characterised by scanning electron microscopy (SEM), Fourier transform infra-red spectroscopy (FTIR) and differential scanning calorimetry (DSC). A commercial diltiazem hydrochloride product Dilzem SR, was used as a reference for comparison

Results: Tablets with only $\mathrm{K}$ or $\mathrm{K} / \mathrm{H}$ had the highest mean dissolution time (MDT), the least dissolution efficiency (DE, $12 \%)$, and released drug by swelling, diffusion and erosion mechanisms. Karaya gum or combinations with locust bean gum sufficiently controlled drug release, while combinations of KH and $K L B H$ exhibited high and low drug release efficiency, respectively. SEM images of the tablets before and after dissolution showed morphological changes on the tablet surface while FTIR and DSC studies indicate that there was no chemical interaction between the drug and the polymers. Three of the formulations compared well with the reference $(p<0.05)$ in terms of release characteristics.

Conclusion: The results of the study demonstrate that karaya gum alone or in suitable combination with locust bean gum and hydroxypropyl methylcellulose is suitable for formulating sustained-release matrix tablets of diltiazem.
\end{abstract}

Key words: Karaya gum, Locust bean gum, Diltiazem hydrochloride, Sustained release, Hydroxypropyl methylcellulose 


\section{INTRODUCTION}

Hydrophilic matrix tablets have long been used as a drug delivery system. This is due to their simplicity, cost-effectiveness, reduced risk of systemic toxicity, and minimal chance of dose dumping. Matrix systems can be used to control the release of both water soluble and water insoluble drugs. On the surface, their drug release behavior appears simple, but the drug release pattern is a complex phenomenon. At the molecular level, it involves water penetration, polymer swelling, as well as drug dissolution, diffusion, swelling, and polymer erosion process [1-3].

In recent years, researchers have become increasingly interested in the utilization of natural biopolymers due to their wide ranging advantages over synthetic polymers. Polysaccharide gums are the materials of choice because they are naturally abundant, biocompatible, biodegradable, and nonimmunogenic [4,5]. Gum karaya, sometimes known as Sterculia gum, is the dried exudate of the Sterculia urens tree and other species of Sterculia. It is a complex polysaccharide of high molecular weight which, on hydrolysis, yields galactose, rhamnose and galacturonic acid. It occurs as a partially acetylated derivative and is compatible with other plant hydrocolloids as well as proteins and carbohydrates. Few works on karaya gum have been reported [6-8].

Locust bean gum (LB), also known as galactomannan, is obtained from the seed of the Locust bean plant, and composed of a 1 , 4-linked $\beta$-D-mannan backbone with 1, 6linked $\alpha-D$-galactose side groups. It is a nonionic molecule consisting of 2,000 residues; the ratio of mannose to galactose in the molecule is $4: 1$. The physicochemical properties of galactomannan are strongly influenced by the galactose content and the distribution of the galactose units along the main chain. The structure contains long stretches of bare mannose backbone (up to 80 D-mannose units long) which is responsible for synergistic interaction with other polymers and its great functionality [911].

HPMC $(H)$ is a widely used semi-synthetic hydrophilic matrix polymer that has been employed in the design of sustained release formulations due to its rapid hydration, good compression and gelling characteristics as well as its ease of use, availability and very low toxicity [12].

Diltiazem hydrochloride (DTZ) is a calcium channel blocker that is widely prescribed for the treatment of hypertension and angina. It is highly water soluble and almost completely absorbed. However, its bioavailability is 30 to $40 \%$ owing to first pass metabolism, and it has an elimination half-life of $3.5 \mathrm{~h}$. Therefore, DTZ requires multiple daily drug dosage in order to maintain adequate plasma concentrations, and is thus a suitable model candidate for sustained drug delivery [13].

The present study investigates karaya gum as a suitable, natural, low-cost hydrophilic matrix material for the formulation of sustained release tablets. Modulation of DTZ release from its matrix tablet using $\mathrm{LB}$ and $\mathrm{H}$ as well as release mechanism were also assessed.

\section{EXPERIMENTAL}

\section{Materials}

Diltiazem hydrochloride (DTZ), microcrystalline cellulose (MCC), and hydroxylpropyl methylcellulose (HPMC K4M) were obtained free of charge from Micro Lab Ltd, Bangalore, India. Locust bean gum (LB) and karaya gum (K) were purchased from Sigma Aldrich, Steinheim, Germany while magnesium stearate, hydrochloric acid, sodium hydroxide, and potassium phosphate monobasic were all obtained from Merck, Mumbai, India. All chemicals were either of pharmaceutical or analytical grade. The reference diltiazem hydrochloride tablet used 
for the study was Dilzem SR (Torrent Pharma Ltd, India).

\section{Preparation of matrix tablets}

Matrix tablets of $100 \mathrm{mg}$ diltiazem hydrochloride were prepared by direct compression method based on the composition shown in Table 1. The excipients (except magnesium stearate) and drug were first passed through $200 \mu$ aperture sieve and then mixed in geometrical dilution for $10 \mathrm{~min}$. Finally, the magnesium stearate was added and mixed for additional $2 \mathrm{~min}$. The batch size of each formulation was 50 tablets. The tablets were compressed in a tablet machine (Rimek Mini Press I) using $12 \mathrm{~mm}$ flat-faced punches.

\section{Characterization of tablets}

The hardness, friability, weight variation, and content uniformity of the compressed matrix tablets were determined. Briefly, hardness was determined using a digital hardness tester (Inwika, Ahmedabad, India) while friability was assessed with a Roche friability testing apparatus. Weight variation and uniformity of drug content were assessed according to Indian Pharmacopoeia (IP) procedures [14]. Twenty tablets were weighed individually and average weight was determined. Not more than two tablets should show a deviation $\pm 5 \%$ of the mean weight. For content uniformity, 10 tablets were selected at random and the mean weight was calculated. The tablets were then powdered and a sample containing $100 \mathrm{mg}$ of the drug was taken in a $100 \mathrm{ml}$ volumetric flask. The volume was made up to mark with simulated gastric fluid (SGF, $0.1 \mathrm{M} \mathrm{HCl}, \mathrm{pH}$ 1.2). A portion of this solution $(7.5 \mathrm{ml})$ was transferred to $100 \mathrm{ml}$ volumetric flask and diluted up to the mark with SGF; $3 \mathrm{ml}$ of this mixture was diluted to $25 \mathrm{ml}$ with SGF, filtered through $0.45 \mu \mathrm{m}$ pore membrane and the absorbance measured spectrophotometrically (model UVPC 1601, Shimadzu, Kyoto, Japan) at $237 \mathrm{~nm}$.

\section{In vitro drug release studies}

Drug release studies were performed using a USP type I apparatus (model TDT-08I, Electrolab, Mumbai, India) at $100 \mathrm{rpm}$ and $37^{\circ} \mathrm{C}$ for the first $2 \mathrm{~h}$ in $900 \mathrm{~mL}$ SGF and then at pH 7.4 in $900 \mathrm{~mL}$ of phosphate buffer for another $10 \mathrm{~h}$. Two millilitres of the dissolution samples were taken at different time intervals and replaced with an equal volume of drug-free dissolution fluid to maintain sink conditions. The samples were suitably diluted with blank dissolution fluid and analyzed for DTZ spectrophotometrically.at $237 \mathrm{~nm}$ [15].

\section{Scanning electron microscopy (SEM)}

The surface morphology of the matrix tablets was analyzed with a scanning electron microscope (JEOL-JSM-840A, Japan).

\section{Water uptake and erosion studies}

Erosion and water uptake of the tableted formulations were determined under conditions identical to those described for dissolution testing using SGF as the medium. Three tablets were used at each time interval. At the predetermined times, the tablets were lightly patted with tissue paper to remove excess surface water. The swollen weight of the tablets was determined (Ts), The tablets were then dried in a vacuum oven at $40{ }^{\circ} \mathrm{C}$ for $48 \mathrm{~h}$ and their dry weight (Tf) was determined. The study was carried out in triplicate. Swelling (\%) and erosion (\%) was calculated using Eqs 1 and 2, respectively [19].

Swelling $(\%)=(T s-T) / T \times 100$

where Ts is the weight of the swollen tablet and $T$ is the initial weight of the tablet, i.e., prior to the test.

Erosion $(\%)=(T-T f) / T f \times 100$ 
where $T$ is the initial weight of the tablet and $\mathrm{Tf}$ is the weight of the tablet after the erosion test.

\section{FT-IR spectroscopy}

In order to evaluate the compatibility of the drug and the polymers used, FT-IR studies were carried out with a Shimadzu FTIR $8400 S$ facility using $\mathrm{KBr}$ pellet to hold the sample.

\section{Thermal analysis}

Thermal analysis was carried out with a differential scanning calorimeter (DSC, Perkin-Elmer, Pyris-1). Scanning was performed at a temperature ranging from 40 to $280{ }^{\circ} \mathrm{C}$ at a heating rate of $10{ }^{\circ} \mathrm{C} / \mathrm{min}$ under an atmosphere of nitrogen. The sample weight was 2 - $4 \mathrm{mg}$ and it was sealed in a perforated aluminium pan.

\section{Kinetic analysis of dissolution data}

To study the mechanism of drug release from the matrix tablets, the release data were fitted to zero-order, first-order, and Higuchi equations. The dissolution data were also fitted to the well-known Korsemeyer exponential equation, which is often used to describe drug release behavior from polymeric systems.

$$
\log \left(M_{t} / M_{f}\right)=\log k+n \log t \ldots \ldots .
$$

The diffusional exponent " $\mathrm{n}$ ", which is indicative of the mechanism of drug release, was obtained by plotting the log value of percent drug released against log time for each batch according to Eq 3. A value of $n=$ 0.45 indicates Fickian (case I) release; > 0.45 but $<0.89$ is non-Fickian (anomalous) release; and > 0.89 indicates super case II type of release. Case II generally refers to the erosion of the polymeric chain, and anomalous transport (non-Fickian) refers to a combination of both diffusion and erosion controlled-drug release. Model-independent approaches, i.e., dissolution efficiency (DE) which is defined as the area under the dissolution curve up to a certain time t, expressed as a percentage of the area of the rectangle described by $100 \%$ dissolution in the same time range, and mean dissolution time (MDT), were used to translate the profile differences into a single value as shown in Eqs 3 and 4 [16, 17].

$$
D E_{12 \%}=\frac{\int_{0}^{t} y d t}{y 100} t \times 100
$$

MDT is a measure of the dissolution rate: the higher the MDT, the slower the release rate.

$$
M D T=\frac{\sum_{i=l}^{i=n} t_{\text {mid }} \times \Delta M}{\sum_{i=l}^{i=n} \Delta M}
$$

where $i$ is the dissolution sample number, $n$ is the number of dissolution sample time, $t_{\text {mid }}$ is the time at the midpoint between $i$ and $i-1$, and $\Delta \mathrm{M}$ is the amount of drug dissolved between $\mathrm{i}$ and $\mathrm{i}-l$. The similarities between two dissolution profiles were assessed by a pair-wise model-independent procedure, similarity factor $\left(f_{2}\right)$.

$$
f_{2}=50 \log \left\{\left[1+\frac{1}{n \sum_{n=1}^{n=i}\left(R_{t}-T_{t}\right)^{2}}\right]^{-0.5} \times 100\right\}
$$

where $n$ is the number of pull points, $R_{t}$ is the reference profile at time point $t$, and $T_{t}$ is the test profile at the same time point; the value of $f_{2}$ should be between 50 and 100. An $f_{2}$ value of 100 suggests that the test and reference profiles are identical and, as the value becomes smaller, the dissimilarity between release profiles increases [18].

\section{Statistical analysis}

Comparison among the developed formulations and the reference formulation (Dilzem SR) were made by Student t-test at 
$95 \%$ level of confidence using Microsoft Office Excel 2007.

\section{RESULTS}

\section{Characterization of tablets}

The compositions of the matrix tablets and the results of the physical characterization of tablets are summarized in Table 1. Tablet friability was less than $1 \%$ while hardness ranged from $4-6 \mathrm{~kg} / \mathrm{cm}^{2}$. Good uniformity in drug content was found among the various formulation batches was drug content was more than $96 \%$ in all cases with less than 1 $\%$ standard deviation. Thus, all the tablet formulations showed acceptable physical characteristics.

Table 1: Composition and physical characteristics of diltiazem hydrochloride (100 mg) matrix tablets

\begin{tabular}{|c|c|c|c|c|c|c|c|c|}
\hline \multicolumn{2}{|c|}{$\begin{array}{l}\text { Formulation \& } \\
\text { code } \\
\text { (drug:polymer) }\end{array}$} & K & LB & $\mathrm{H}$ & MCC & $\begin{array}{c}\text { Hardness } \\
\left(\mathbf{k g} / \mathrm{cm}^{2}\right) \\
\pm S D\end{array}$ & $\begin{array}{c}\text { Friability } \\
\text { (\%) }\end{array}$ & $\begin{array}{c}\text { Assay (\%) } \\
\pm \text { SD }\end{array}$ \\
\hline $\mathrm{K}(1: 1)$ & $\mathrm{F} 1$ & 100 & - & - & 390 & $5.7 \pm 0.6$ & 0.35 & $97.0 \pm 0.7$ \\
\hline$K(1: 2)$ & F2 & 200 & - & - & 290 & $5.6 \pm 0.5$ & 0.31 & $98.0 \pm 0.6$ \\
\hline$K(1: 4)$ & F3 & 400 & - & - & 90 & $5.3 \pm 0.6$ & 0.46 & $99.0 \pm 0.7$ \\
\hline $\operatorname{KLB}(1: 1)$ & F4 & 50 & 50 & - & 390 & $5.3 \pm 0.4$ & 0.49 & $99.0 \pm 0.6$ \\
\hline $\operatorname{KLB}(1: 2)$ & F5 & 100 & 100 & - & 290 & $5.1 \pm 0.6$ & 0.59 & $101.0 \pm 0.8$ \\
\hline $\operatorname{KLB}(1: 4)$ & F6 & 200 & 200 & - & 90 & $4.8 \pm 0.7$ & 0.65 & $97.0 \pm 0.5$ \\
\hline $\mathrm{KH}(1: 1)$ & F7 & 50 & - & 50 & 390 & $5.7 \pm 0.4$ & 0.30 & $98.0 \pm 0.6$ \\
\hline $\mathrm{KH}(1: 2)$ & F8 & 100 & - & 100 & 290 & $5.7 \pm 0.4$ & 0.36 & $98.0 \pm 0.5$ \\
\hline $\mathrm{KH}(1: 4)$ & F9 & 200 & - & 200 & 90 & $5.8 \pm 0.3$ & 0.42 & $98.0 \pm 0.6$ \\
\hline $\operatorname{KLBH}(1: 1$ & $\mathrm{F} 10$ & 50 & 25 & 25 & 390 & $5.5 \pm 0.4$ & 0.45 & $98.0 \pm 0.7$ \\
\hline $\mathrm{KLBH}(1: 2$ & $F 11$ & 100 & 50 & 50 & 290 & $5.7 \pm 0.5$ & 0.5 & $99.0 \pm 0.4$ \\
\hline & $F 12$ & 200 & 100 & 100 & 90 & $5.6 \pm 0.4$ & 0.58 & $97.0 \pm 0.5$ \\
\hline \multicolumn{2}{|c|}{$\begin{array}{l}\text { KLBH(1:4) } 112 \\
\text { Reference }\end{array}$} & \multicolumn{4}{|c|}{ Dilzem- SR } & $5.8 \pm 0.1$ & 0.28 & $98.0 \pm 0.1$ \\
\hline
\end{tabular}

Note: Magnesium.stearate (10 mg/tablet) was added as glidant-lubricant to all the tablet formulations

Table 2: Kinetic parameters of the dissolution data

\begin{tabular}{cccccc}
\hline Formulation & $\mathbf{n}$ & Peppas & Higuchi & $\begin{array}{c}\text { MDT(h) } \pm \\
\text { SD }\end{array}$ & $\begin{array}{c}\mathbf{D E}_{12} \% \pm \\
\text { SD }\end{array}$ \\
\hline F1 & 0.4784 & 0.998 & 0.9652 & $3.56 \pm 0.20$ & $55.69 \pm 3.02$ \\
F & 0.4967 & 0.9929 & 0.9891 & $3.69 \pm 0.10$ & $45.17 \pm 1.47$ \\
F3 & 0.6214 & 0.9916 & 0.9898 & $4.03 \pm 0.20$ & $37.67 \pm 5.10$ \\
F4 & 0.0679 & -- & --- & $0.87 \pm 0.30$ & $90.98 \pm 6.12$ \\
F5 & 0.5248 & 0.9808 & 0.9768 & $3.52 \pm 0.10$ & $58.02 \pm 4.15$ \\
F6 & 0.5861 & 0.981 & 0.9743 & $3.82 \pm 0.20$ & $49.22 \pm 3.17$ \\
F7 & 0.4956 & 0.9932 & 0.879 & $3.07 \pm 0.30$ & $52.63 \pm 6.14$ \\
F8 & 0.5896 & 0.9808 & 0.9856 & $3.89 \pm 0.20$ & $44.03 \pm 1.29$ \\
F9 & 0.6321 & 0.988 & 0.9874 & $4.54 \pm 0.20$ & $34.37 \pm 2.61$ \\
F10 & 0.5335 & 0.9962 & 0.9281 & $3.38 \pm 0.20$ & $64.5 \pm 9.15$ \\
F11 & 0.5830 & 0.997 & 0.9361 & $3.42 \pm 0.20$ & $48.79 \pm 2.88$ \\
F12 & 0.6889 & 0.7755 & 0.9844 & $3.80 \pm 0.20$ & $39.46 \pm 4.51$ \\
Reference & 0.5531 & 0.999 & 0.9862 & $3.54 \pm 0.10$ & $59.82 \pm 3.12$ \\
\hline
\end{tabular}




\section{In vitro drug release and kinetic analysis}

The release profiles of the tablets made with $K$ and KLB blend are presented in Figure $1 A$. The initial drug released in the 1st hour ranged from $13-26 \%$ for $\mathrm{K}$ formulations but at the end of $12 \mathrm{~h}$, the value rose to between 50 and $81 \%$, indicating that the tablets extended release for more than $12 \mathrm{~h}$. For matrix tablets formulated with KLB polymer blend in 1:1 (drug: polymer) ratio, the initial release in the 1st hour ranged from $18-83$ $\%$. At the end of $12 \mathrm{~h}$, the figure was between 75 and $98 \%$. The release profiles of the tablets made with polymer blends $\mathrm{KH}$ and $\mathrm{KLBH}$ are presented in Figure 1B. The tablets containing $\mathrm{KH}$ blend in $1: 1$ ratio as the matrix (i.e., formulations F7, F8 and F9) showed 15 - $24 \%$ release in the first hour and a cumulative release of $48-71 \%$ at the end of $12 \mathrm{~h}$. On the other hand, the tablets containing the polymer blend $\mathrm{K}: \mathrm{LB}: \mathrm{H}$ (1.0:0.5:0.5) as the matrix showed a cumulative release of $53-92 \%$ at the end of $12 \mathrm{~h}$.
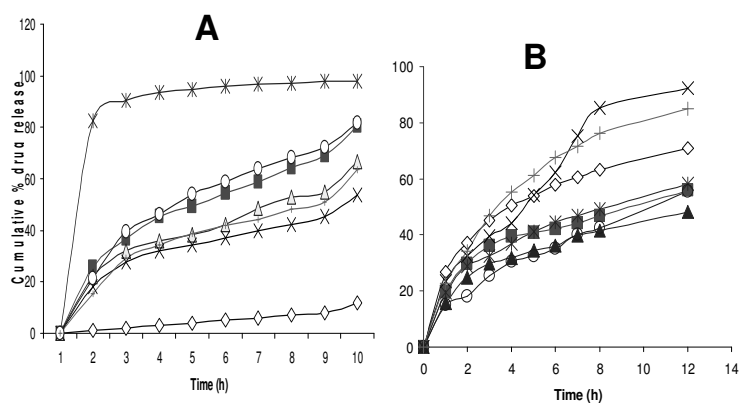

Figure 1: Dissolution profile of formulations.

(Note: For $A, \diamond=F 1 ; \boldsymbol{\square}=F 2 ; \Delta=F 3 ; x=F 4$; $*$ =F5; $O=F 6$, while for $B, \diamond=F 7 ; \boldsymbol{\square}=F 8$; $\boldsymbol{\Lambda}=$ $F 9 ; X=F 10 ; *=F 11 ; O=F 12 ;+=D I L)$

The results of kinetic analysis of the dissolution data, mean dissolution time (MDT) and $\mathrm{DE}_{12}$ of all the formulations are shown in Table 2. MDT values ranged from 0.87 - $4.54 \mathrm{~h}$ while dissolution efficiency $\left(\mathrm{DE}_{12}\right)$ at the end of $12 \mathrm{~h}$ was $34-91 \%$. The drug release data of the tablet formulations did not fit satisfactorily to zero-order, firstorder, and Higuchi models but showed good fit to the Korsmeyer model $\left(r^{2}=0.9652\right.$ to 0.9976) and to some degree the Higuchi model $\left(r^{2}=0.879\right.$ to 0.9898$)$. The value of the release exponent, " $n$ ", for the various matrices ranged from 0.4700 to 0.6889 . F5 had MDT and dissolution efficiency ( $\left.\mathrm{DE}_{12} \%\right)$ similar to those of the standard product, Dilzem SR. The similarity factor $\left(f_{2}\right)$ was 77.86, suggesting that their dissolution profiles were very similar.

\section{Scanning electron microscopy (SEM)}

Figure 2 displays the scanning electron micrographs showing the surface morphology of formulation F5. The SEM photos show that the surface of the matrix tablet was highly porous.
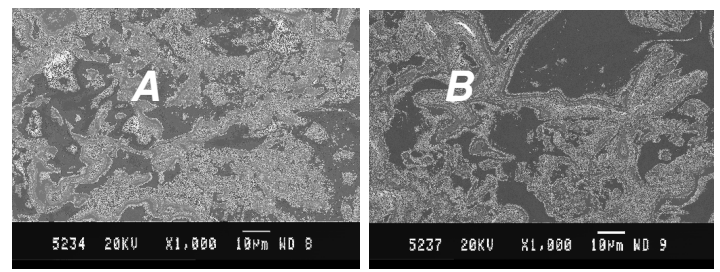

Figure 2: SEM photographs of formulation F5 before $(A)$ and after dissolution $(B)$

\section{Water uptake and erosion}

Figure 3 shows the water uptake and erosion profiles of optimized formulation F5 and reference. Tablet swelling and erosion at the end of $12 \mathrm{~h}$ was 172 , and $250 \%$. 33.4 and $33 \%$, respectively.

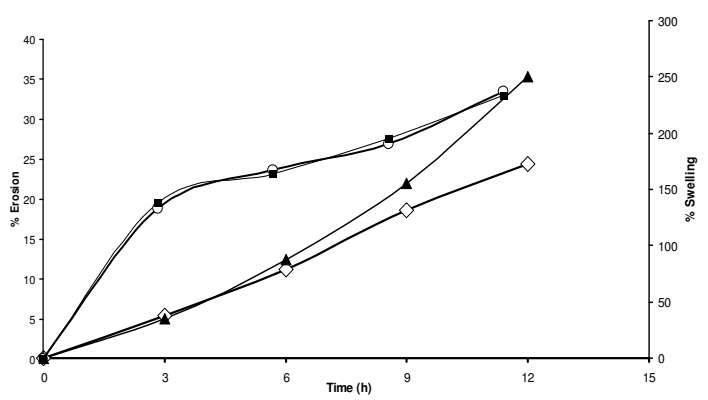

Figure 3: Swelling and eroding behaviour of formulation F5 $(\diamond, \bigcirc)$ and reference formulations $(\triangle, \boldsymbol{\nabla})$ 


\section{FT-IR spectroscopy}

The FTIR spectra of both the pure drug and one of the matrix formulations (not presented here) showed characteristic peaks at 3433.13 $\mathrm{cm}^{-1}$ (aliphatic $\mathrm{C}-\mathrm{H}$ stretching), $2931.90 \mathrm{~cm}^{-1}$ (O-CH3, C-H stretching), $2387.93 \mathrm{~cm}^{-1}$ (amine $\mathrm{HCl}, \mathrm{N}-\mathrm{H}$ stretching), $1741.78 \mathrm{~cm}^{-1}$ (acetate $\mathrm{C}=\mathrm{O}$ stretch), $1678.13 \mathrm{~cm}^{-1}$ (lactam $\mathrm{C}=\mathrm{O}$ stretch), $831.33 \mathrm{~cm}^{-1}$ (O-substituted aromatic $\mathrm{C}-\mathrm{H}$ out of plane-deformation), $773.48 \mathrm{~cm}^{-1}$ (p-substituted aromatic $\mathrm{C}-\mathrm{H}$ out of plane-deformation) thus indicating that there was no drug-polymer interaction in the formulation.

\section{Thermal analysis}

The DSC thermograms of one of the formulations and pure DTZ showed endothermic peaks for the pure DTZ and the DTZ in the formulation at 217.4 and $218.9^{\circ} \mathrm{C}$, respectively.

\section{Release analysis}

Of all the formulations, only $\mathrm{F} 1, \mathrm{~F} 5$, and F10 did not significantly differ in terms of drug release $(p<0.05)$ from the commercial DTZ product used as standard.

\section{DISCUSSION}

The matrix tablets exhibited satisfactory mechanical characteristics based on the friability and hardness data presented. Content uniformity was also good. The slower and more sustained drug release from khaya (K) formulation (F3), compared to the control, can be attributed to high gum hydration with concurrent swelling, followed by gradual erosion. This appears to be confirmed by higher MDT and lower dissolution efficiency. In matrix tablets containing a mixture of polymers $K$ and $L B$ in a ratio of $1: 1$, drug release increased as the amount of polymer blend decreased. Formulations F5 and F6 showed extended drug release over a period that exceeded $12 \mathrm{~h}$. Formulation F4 (K:LB in $1: 1$ ratio) showed the most rapid release (83
$\%$ in $1 \mathrm{~h})$, the least MDT (0.8 h) and highest dissolution efficiency (99\% after 12 h) thus indicating that this polymer mixture was unable to sustain drug release. This may be explained as follows. Studies have shown that LB gum is less soluble and viscous than khaya gum as it has fewer galactose branch points. Thus, the hydrated matrix lacked gel integrity, resulting in higher erosion. An earlier stidy indicates that LB displayed a high erosion rate and low swelling than $\mathrm{K}$ [20]. The matrrices containing a mixture of $\mathrm{K}$ and $H$ in 1:1 ratio (F7, F8 and F9) showed more pronounced sustained release than those containing $\mathrm{K}$ alone and $\mathrm{K} / \mathrm{LB}$ blend when compared to HPMC. This is probably due to the fact that $\mathrm{K}$ and LB gums are more hydrophilic, and, therefore showed greater water uptake and erosion than $\mathrm{H}$ (i.e., HPMC). Thus, the HPMC in the blend increased the integrity and resistance of the matrix to erosion. Furthermore, the high viscosity of the gel formed resulted in longer diffusional path length, thus retarding drug diffusion and resulting in high MDT values. Therefore, there is synergism between khaya gum and HPMC to effect sustained release. This is in agreement with earlier results obtained for karaya gum [15] and LB matrices [11]. Formulation of triple mixtures is capable of sustaining drug release considering their MDT. However, the 2 polymer blends or $\mathrm{K}$ alone, showed release profiles similar to the reference commercial formulation, indicating there was no synergism between the 3 polymers [19].

The release data showed high linearity with the Korsmeyer model. The values of release exponent " $n$ " were characteristic of anomalous kinetics (non-Fickian) and indicate a combined effect of diffusion and erosion mechanisms for controlled drug release. For all the formulations, there was contribution from polymer relaxation to the dissolution process as " $n$ " value approaches anomalous transport. Relaxational contribution was higher for the formulations with higher " $n$ " values [10]. 
The SEM photomicrograph of the tablets $8 \mathrm{~h}$ after hydration commenced showed a highly porous tablet surface which probably also reflects a porous tablet matrix structure. This would facilitate diffusion of drug from the tablet core to the surface. Since the gel layer undergoes surface erosion, it is possible that the inner porous network is exposed after the dissolution of the outer layer of the matrix. The formation of both pores and gel structure on the tablet surface indicates involvement of both erosion and diffusion mechanisms for sustained drug release [16].

Thus, the matrices underwent both swelling and erosion at the same time immediately after placement in the dissolution medium, and this continued over the $12 \mathrm{~h}$ period of the study. Formulation F5 and the reference DTZ had overlapping erosion profiles throughout the study period but their swelling behaviour were similar only up to the 6th hour. However, the swelling profile of F5 was similar to those reported earlier for K, LB and xanthan matrices containing a different water soluble drug [20].

The FTIR spectra of the pure drug and the test formulation showed characteristic peaks for both pure DTZ and DTZ in the test formulation without any significant shift in their positions. Also, the DSC endothermic peaks for the pure drug and the drug in the test formulation showed only a negligible shift in their positions with some peak broadening in the latter. Thus, the likelihood of any chemical interaction between the drug and the polymers used can be ruled out.

\section{CONCLUSION}

Previous studies have shown locust bean gum alone cannot efficiently control drug release. This study demonstrates that its combination with khaya gum is synergistic in controlling diltiazem release. Combination of khaya gum with HPMC led to even greater sustained than khaya gum or its combination with locust bean LB gum. Based on a derived dissolution parameter, $f_{2}$, the formulation containing khaya and locust bean gums in a ratio of 1:2 (i.e., F5) was closest to the commercial diltiazem tablet used as standard. Thus, a suitable combination of the two natural gums (khaya amd locust bean gums/ may be successfully employed for formulating sustained-release matrix tablets of diltiazem.

\section{ACKNOWLEDGEMENT}

The authors wish to thank J.S.S. Mahavidyapeetha, Mysore and JSS University, Mysore, India, for their valuable support during this research. The authors also express their thanks to IISC, Bangalore for providing facilities for SEM and DSC studies

\section{REFERENCES}

1. Viriden $A$, Wittgren $B$, Larsson A. Investigation of critical polymer properties for polymer release and swelling of HPMC matrix tablets. Eur $J$ Pharm Sci 2009; 36: 297-309.

2. Elmowafy EM, Awad GA, Mansour S, El-Shamy AE. Release Mechanisms Behind Polysaccharides-Based Famotidine Controlled Release Matrix Tablets. AAPS PharmSciTech 2008; 9(4): 1230-1239.

3. Hiremath PS, Saha RN. Controlled Release Hydrophilic Matrix Tablet Formulations of Isoniazid: Design and In Vitro Studies. AAPS PharmSciTech 2008; 9(4): 1171-1178.

4. Bhardwaj TR, Kanwar M, Lal R, Gupta A. Natural gums and modified natural gums as sustainedrelease carriers. Drug Dev Ind Pharm 2000; 26(10): 1025-1038.

5. Coviello T, Matricardi P, Marianecci C, Alhaique F. Polysaccharide hydrogels for modified release formulations. J Control Release 2007119 :524.

6. Barakat NS, Elbagory IM, Almurshedi AS. Controlled-Release Carbamazepine Granules and Tablets Comprising Lipophilic and Hydrophilic Matrix Components. AAPS PharmSciTech 2008 ; 9(4): 1054-1062.

7. Verbeken D, Dierckx S, Dewettinck K. Exudate gums: occurrence, production, and applications. Appl Microbiol Biotechnol 2003; 63(1):10-21.

8. Deshmukh VN, Jadhav JK, Sakarkar DM., 2009, Formulation and in vitro evaluation of theophylline anhydrous bioadhesive tablets. Asia J Pharm 2009; 3: 54-58.

9. Rizzo V, Tomaselli F, Gentile A, La MS, Maccarone E. Rheological properties and sugar

Trop J Pharm Res, June 2010; 9 (3):290 
composition of locust bean gum from different carob varieties (Ceratonia siliqua L.). J Agric Food Chem 2004 29; 52 : 7925-7930.

10. Venkatraju MP, Gowda DV, Rajesh $K R$, Shivakumar HG. Xanthan \& locustbean gum (from ceratonia -siliqua) matrix tablets for oralcontrolled delivery of metaprolol $\mathrm{HCl}$. Current drug therapy 2008; 3(1): 85-93

11. Rajesh KS, Venkataraju MP, Gowda DV. Effect of hydrophilic natural gums in formulation of oralcontrolled release matrix tablets of propranolol hydrochloride. Pak J Pharm Sci 2009; 22(2): 211-9.

12. Meyyanathan $S N$, Rajan $S$, Muralidaharan $S$, Siddaiah MK, Krishnaraj $K$, Suresh $B$. Formulation and evaluation of dextromethorphan hydrobromide sustained release tablets. Drug Deliv 2008; 15(7): 429435.

13. Gambhire $M N$, Ambade KW, Kurmi SD, Kadam VJ, Jadhav KR. Development and in vitro evaluation of an oral floating matrix tablet formulation of diltiazem hydrochloride. AAPS PharmSciTech 2007; 8(3): E1-E9.

14. Government of India Ministry of Health and Family Welfare; The Pharmacopoeia of India 1996, Volume II; New Delhi; Controller of Publication; pp $734-736$

15. Odeku OA, Fell JT. Effects of the method of preparation on the compression, mechanical, and release properties of khaya gum matrices. Pharm Dev Technol 2006; 11(4): 435-441.

16. Durig $T$, Fassihi $R$. Guar-based monolithic matrix systems: effect of ionizable and non-ionizable substances and excipients on gel dynamics and release kinetics. J Control Release 2002; 80: $45-56$.

17. Kuksal A, Tiwary AK, Jain NK, Jain S. Formulation and in vitro, in vivo evaluation of extendedrelease matrix tablet of zidovudine: influence of combination of hydrophilic and hydrophobic matrix formers. AAPS PharmSciTech 2006; 7(1): E1-E9.

18. Costa P, Sousa Lobo JM, Gohel MC, Panchal MK. Modeling and comparison of dissolution profiles. Eur J Pharm Sci 2001; 13(2): 123133.

19. Varshosaz J, Tavakoli N, Kheirolahi F. Use of hydrophilic natural gums in formulation of sustained-release matrix tablets of tramadol hydrochloride. AAPS PharmSciTech 2006; 7(1): E1-E7.

20. Sujja-areevath J, Munday DL, Cox PJ, Khan KA. Relationship between swelling, erosion and drug release in hydrophillic natural gum minimatrix formulations. Eur J Pharm Sci 1998; 6: 207-217. 